\title{
TIGE IS THE MAN
}

\author{
An old-fashioned night out.
}

\section{BY SUE LANGE}

$\mathrm{T}$ ige is the man and he knows it. Mr Personality. Sharp-tie-wearing, punchline-busting, girl-sweet-talking. Everybody loves him; he puts up such a good front. And his parties? Sublime.

Tonight he's gone all out, giving the cats something they've never tasted. A trip into the past when things were dicey and anything could happen. Not like today where you know what's going to happen even before it does.

The guests arrived at Tige's in twos, couples holding tight as if in love. As if someday they'd reveal themselves to their one and only. Expose their naked feelings to their significant other late at night, maybe, when the curtains were closed and the children were in bed.

He watched them and wondered and laughed to himself. He wasn't even drunk yet, but he laughed, because he knew that before the night was through all would be revealed.

He'd spiked the rum punch with floating hothouse gardenias. He'd padded each ash-tray with green marijuana spliffs. His house delivery system was set to a groovalicious pop rock. The beat, key and bassline changed with each new arrival at the door. As the guests entered, they let their guard down for half a mo' so that the house could read their minds and respond with the appropriate musical vibe. The evening was electric.

At ten, the games began.

"Let us hark back to the age of chivalry," Tige said from his post in front of the defunct fireplace in the wall of his condo. He had a malicious grin on his face when he said: "When goils were goils, and men were men."

Everyone knew the bit of mass culture he was referring to. They knew it all by heart. And if they didn't, they could check it remotely, instantaneously.

Tige continued. "I'm talking about the late twentieth, ladies and gents. Back when

$\rightarrow$ NATURE.COM Follow Futures on Facebook at: go.nature.com/mtoodm people had open minds. Privacy was their birthright. It was easy to be a man or a goil back then."

They laughed again.
They didn't really know why. But the words sounded funny so they laughed.

"They had party games like we do, but they were different," Tige said. "They played Charades and Pin the Tail on the Donkey instead of our games like My 15 Minutes

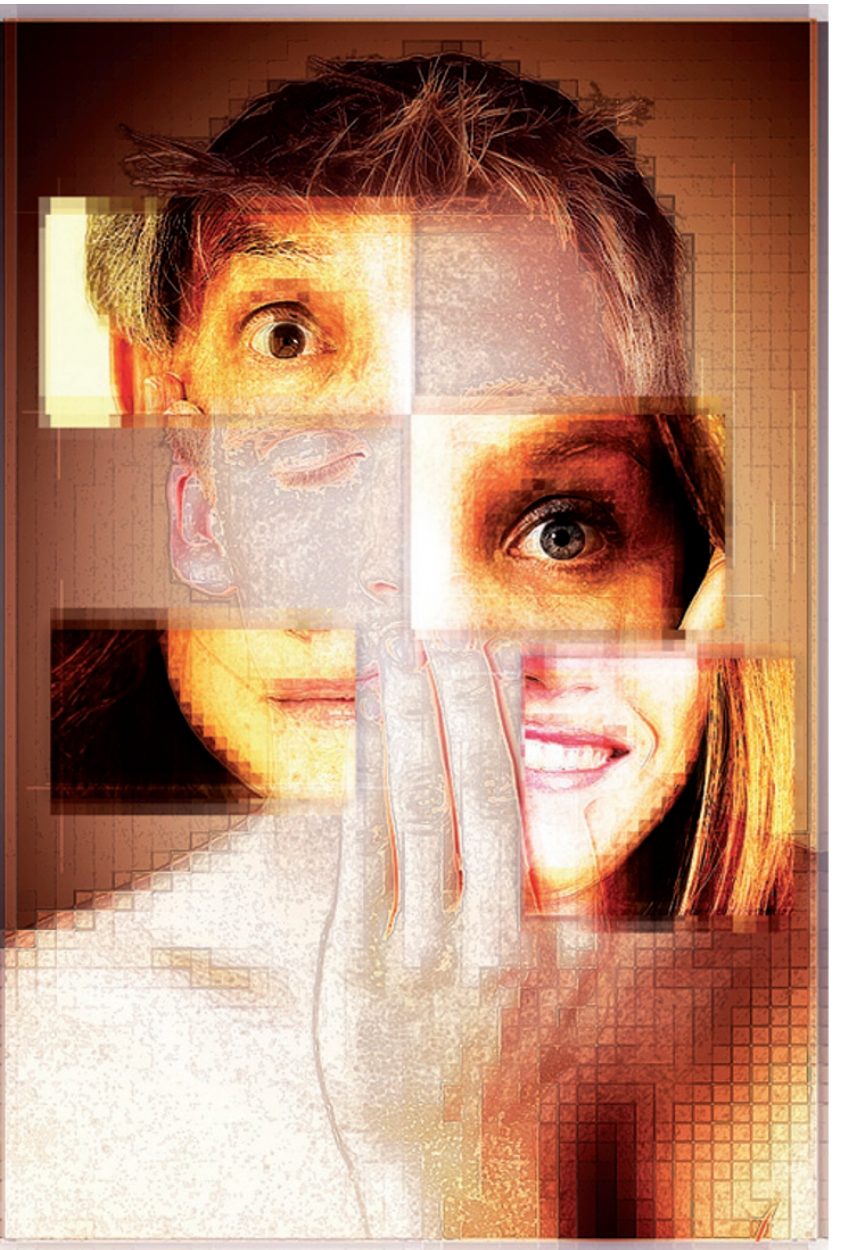

or Pass the Vid. There was one such oddity called Truth or Dare, and that's the one we'll hark back to tonight. It's all about daring to tell the truth. And daring to believe it. Remember boys and goils, it was a leap of faith back then. Back then, no one could check. Nowadays ..." Tige moved his eyebrows up and down as if he was peeking under somebody's skirt.

"Und so!" he shouted with finger pointing to the ceiling. "Tonight we check!"

He waved his hands in the air, beckoning to the house and its mind-readingware installed in the walls. "The very latest in Sony Hive-Mind tech," he said, as if that was a statement, information they needed because they couldn't have guessed that Tige wouldn't be caught dead without the latest in anything.

“Tonight we make history," Tige declared. "For the first time in humanity's long flight from the trees, we dare to be truthful."

And with one final flourish, he passed his hand in front of his face and let down his guard.

The crowd of half-drunk, halfhigh, neo-hip-cons gasped. One young girl tittered as she saw something she'd never seen before: a big long thought. Tige remained steadfast even as his face turned a bit rose. He grew bolder and took in the faces of his guests, passing judgments as he scanned. They could see what he thought of them, who he liked and who he'd screwed and who he'd rather see dead.

They laughed and cried, guffawed and swore; he made some enemies in a quick five minutes. But his fears slowly left him and his conscience ran clear. A smile spread across his face. He felt fine.

"Come on in, my friends," he said. "It's great! A little draughty in the old noggin maybe, but in general I feel fine."

The crowd remained silent and thoughtful for a moment only and then they, not wanting to be left behind at the avant-garde event of the year, likewise passed their hands in front of their faces with a flourish. They let slip their shields and revealed what lay behind.

The house extracted the contents of their minds and published them in Tige's room. They pointed at each other and giggled with hands over their mouths as if trying to hold back thoughts that burbled out. Some turned scarlet; one man ran to the bathroom and cried. The more they drank, though, the more they howled. A good time was had by all.

At five in the morning, when dawn threatened to break, they sobered up and replaced the shields. They cleared their throats, adjusted their caps, straightened their skirts. One by one, they left alone.

Sue Lange is a writer living in Pennsylvania. Her parties are not to be missed. 